\title{
High-resolution NMR spectroscopy of encapsulated proteins dissolved in low-viscosity fluids
}

\author{
Nathaniel V. Nucci, Kathleen G. Valentine, and A. Joshua Wand ${ }^{*}$ \\ Department of Biochemistry and Biophysics and Johnson Research Foundation, University of \\ Pennsylvania Perelman School of Medicine, Philadelphia, PA 19104-6059, USA
}

\begin{abstract}
High-resolution multi-dimensional solution NMR is unique as a biophysical and biochemical tool in its ability to examine both the structure and dynamics of macromolecules at atomic resolution. Conventional solution NMR approaches, however, are largely limited to examinations of relatively small $(<25 \mathrm{kDa})$ molecules, mostly due to the spectroscopic consequences of slow rotational diffusion. Encapsulation of macromolecules within the protective nanoscale aqueous interior of reverse micelles dissolved in low viscosity fluids has been developed as a means through which the 'slow tumbling problem' can be overcome. This approach has been successfully applied to diverse proteins and nucleic acids ranging up to $100 \mathrm{kDa}$, considerably widening the range of biological macromolecules to which conventional solution NMR methodologies may be applied. Recent advances in methodology have significantly broadened the utility of this approach in structural biology and molecular biophysics.
\end{abstract}

\section{Keywords}

reverse micelle NMR; protein encapsulation; nucleic acid encapsulation; low viscosity fluid; structural biology; biophysics

\section{Introduction}

Nuclear magnetic resonance (NMR) spectroscopy continues to play a central role in the characterization of the structure and dynamics of proteins, nucleic acids and their complexes. Over the past several decades developments in solution NMR techniques, especially triple resonance spectroscopy and supporting technologies, have made the comprehensive structural characterization of $20 \mathrm{kDa}$ soluble proteins routine [1]. Solution NMR spectroscopy can provide a detailed view of the solution structure of macromolecules and allows unparalleled access to dynamic phenomena. It also provides a unique avenue to monitor the full structural and dynamic effects of changes in temperature, pressure, and

"Corresponding Author: Professor A. Joshua Wand Department of Biochemistry \& Biophysics University of Pennsylvania Perelman School of Medicine 904 Stellar-Chance Laboratories 422 Curie Blvd. Philadelphia, Pennsylvania 19104-6059 wand@mail.med.upenn.edu 215-573-7288 (office) 215-573-7291 (fax).

Disclosure

AJW declares a competing financial interest as a Member of Daedalus Innovations, LLC, a manufacturer of reverse micelle and highpressure NMR apparatus. 
other solution conditions including the binding of small and large ligands. With the development of multinuclear and multidimensional NMR, the structures of proteins of significant size and spectral complexity can now be efficiently determined. However, increasing molecular size leads to slower tumbling and correspondingly shorter spin-spin relaxation times $\left(\mathrm{T}_{2}\right)$. Short $\mathrm{T}_{2}$ values severely limit the power and flexibility of multiple pulse NMR experiments in at least two ways. The signal-to-noise ratio of a Lorentzian line degrades with decreasing $T_{2}$ and the effectiveness of the library of conventional multidimensional and multinuclear NMR experiments are exponentially sensitive to $T_{2}$ [1]. Accordingly, the standard triple resonance experiments become unreliable at room temperature for proteins larger than $30 \mathrm{kDa}$ and largely fail for proteins above $35 \mathrm{kDa}$ in the absence of elevated temperature and/or extensive deuteration. A variety of approaches have been developed to combat the limitations caused by fast transverse relaxation brought about by slow molecular reorientation where the combination of perdeuteration with selective reprotonation [2-4] and the transverse relaxation optimized (TROSY) spectroscopy [5, 6] has enabled access to an array of insights into very large macromolecular complexes. Nevertheless, this basic approach does come with costs both with respect to the production of material and loss of potential information resulting from extensive perdeuteration.

It was in this context some fifteen years ago that we introduced an alternate strategy that focused on attacking the origin of the "slow tumbling problem" presented by large macromolecules [7]. That is the inescapable fact that the larger the protein is the more slowly it tumbles in free aqueous solution. Slower macromolecular reorientation leads to faster spin-spin relaxation and therefore broader resonances and poorer coherence transfer in multi-dimensional experiments. Briefly, if we consider a heteronuclear spin pair such as an amide ${ }^{15} \mathrm{~N}-{ }^{1} \mathrm{H}$, we find that the spin-spin relaxation rate $\left(\mathrm{R}_{2}\right)$ is:

$$
\begin{aligned}
R_{2}= & \left(\frac{1}{T_{2}}\right)=\left(\frac{\mu_{0}}{4 \pi}\right)\left(\frac{h^{2} \gamma_{N}^{2} \gamma_{H}^{2}}{6 r^{6}}\right)\left[4 J(0)+J\left(\omega_{H}-\omega_{N}\right)+6 J\left(\omega_{H}\right)+3 J\left(\omega_{N}\right)+J\left(\omega_{H}+\omega_{N}\right)\right] \\
& +\frac{\omega_{N}^{2} \Delta \sigma^{2}}{18}\left[4 J(0)+3 J\left(\omega_{N}\right)\right]
\end{aligned}
$$

where $\mathrm{J}(\omega)$ is the spectral density at frequency $\omega, \mathrm{r}$ is the effective $\mathrm{N}-\mathrm{H}$ bond length, and the remaining symbols have their usual meanings. It is useful to express the spectral densities in terms of the popular Lipari-Szabo (L-S) model-free treatment [8] to make the dependence of the spin-spin relaxation rate on the time scale of macromolecular tumbling clear. For an isotropically reorienting macromolecule, the L-S model-free spectral density is:

$$
J(\omega)=\frac{2}{5}\left[\frac{O^{2}}{1+\omega^{2} \tau_{m}^{2}}+\frac{\left(1-O^{2}\right)}{1+\omega^{2} \tau^{2}}\right] \quad ; \quad \tau^{-1}=\tau_{m}^{-1}+\tau_{e}^{-1}
$$

where $O^{2}, \tau_{\mathrm{e}}$ and $\tau_{\mathrm{m}}$ are the model-free squared generalized order parameter, effective correlation time and macromolecular reorientation correlation time, respectively. Thus, in the absence of complete disorder (i.e. $O^{2} \rightarrow 0$ ), the spin-spin relaxation will be heavily influenced by the time scale of macromolecular tumbling. 
The key ingredient leading to an alternate approach to the slow tumbling problem is revealed by the Stokes-Einstein equation which describes the molecular reorientation time of a spherical particle in a solvent of much smaller molecules:

$$
\tau_{m}=\frac{4 \pi r^{3} \eta}{3 k_{B} T}
$$

where $\tau_{m}$ is the rotational correlation time, $k_{B}$ is the Boltzmann constant, $T$ is the temperature, $\eta$ is the viscosity of the liquid, and $r$ is the radius of the particle. Obviously, the larger the particle is the more slowly it will tumble. Consideration of Equation 3 suggests three possible routes to alleviating the slow tumbling of a macromolecule such as a protein. A classic approach is to reduce the volume of the protein by examination of fragments that can be made in various ways. This reductionist strategy, though often advantageous, has begun to fall out of favor in modern-day structural biology and biophysics. Using elevated temperature is an enticing possibility since it will increase the thermal energy $\left(\mathrm{k}_{\mathrm{B}} \mathrm{T}\right)$ available for molecular reorientation, activate internal motion and reduce the viscosity of water all of which will tend to reduce the spin-spin relaxation rate. Unfortunately, however, most biological macromolecules are stable at only modestly elevated temperatures making this tactic of limited utility.

One variable in Equation 2 remains - the viscosity. The strategy then becomes to find a means to "trick" the protein of interest by providing it with a stabilizing hydration shell and dissolving the entire assembly of protein and hydration water in a low viscosity solvent. Methods have been developed to solubilize proteins with minimal water directly in organic solvents but only at very low concentrations that are unsuitable for NMR spectroscopy [9, 10]. To protect and solubilize individual hydrated protein molecules, we turned to the reverse micelle encapsulation technology developed for a variety of applications during the 1980s [11]. The goal was to adapt reverse micelle encapsulation to the stringent requirements of high-resolution solution NMR: maintenance of structural integrity, sufficient concentrations of macromolecule (i.e. near $\mathrm{mM}$ ) and low enough bulk solvent viscosity to enhance the NMR performance by suppression of spin-spin relaxation through increased macromolecular tumbling.

\section{Reverse micelles for encapsulation of macromolecules}

Under appropriate conditions, mixtures of surfactants and a small volume of water immersed in a bulk non-polar solvent such as the alkanes will spontaneously organize into spherical reverse micelles (Figure 1) [12]. Surfactants capable of forming spherical reverse micelles generally have small polar or charged headgroups and long and often branched hydrophobic tails. Under conditions appropriate for solution NMR, each reverse micelle will contain 100-400 primary surfactant molecules, one to five thousand waters, and a single protein molecule. The size of the aqueous nanoscale water core of the reverse micelle is largely influenced by the molar ratio of water to surfactant molecules, which is often termed the water-loading or $W_{0}$. These mixtures can form a range of structures ranging from small nanometer scale spherical particles to macroscopic gels. The phase diagram is often complex and dependent on a variety of parameters such as water loading, temperature, pressure, 
absolute surfactant concentrations and ratios and so on e.g. [13]. Reverse micelle encapsulation has long been used for investigations of protein structure and function using relatively low-resolution spectroscopic methods such as ultraviolet-visible absorption and fluorescence emission spectroscopy [11,12] The concentrations of encapsulated protein required for these studies are generally much lower $(\sim \mu \mathrm{M})$ than that needed for efficient investigation by NMR ( mM).

Protein and peptide molecules encapsulated within reverse micelles were first examined using simple solution NMR methods over two decades ago [14, 15]. One-dimensional NMR measurements of proteins in reverse micelles offered more conclusive evidence of the maintenance of protein structural integrity, indicating the potential of this approach for highresolution solution NMR investigations. These early studies largely utilized reverse micelles comprised of the surfactant bis(2-ethylhexyl)sulfosuccinate (AOT) and were typically prepared in the relatively high-viscosity iso-octane. Since the radius of the reverse micelle is substantially larger than the radius of the protein (Figure 1), the viscosity of the nonpolar solvent therefore becomes a vital parameter for solution NMR of the encapsulated macromolecules. Unfortunately, there are very few solvents that are capable of supporting the formation of small reverse micelles and are of low enough viscosity to overcome the volume penalty imposed by encapsulation (Figure 2). The short chain alkanes [7], carbon dioxide [16] and xeon [17] have been examined in this context.

Historically, AOT has been widely used presumably because it can form stable reverse micelles over a broad range of surfactant concentrations and water content. Unfortunately, efforts to encapsulate proteins with high structural fidelity in AOT reverse micelles revealed that this surfactant has a strong denaturing effect on most proteins [18]. Several other surfactant mixtures have been developed for high-resolution NMR studies of encapsulated proteins. These surfactants and their ${ }^{1} \mathrm{H}$ spectra are illustrated in Figure 3. Each of these surfactants contains distinct ${ }^{1} \mathrm{H}$ signals that permit detailed analysis of sample compositions such as the precise surfactant ratios and measurement of $W_{0}$. For high-resolution NMR studies, however, the advantages of AOT are overwhelmed by its strong propensity to denature encapsulated proteins. For the purposes of protein biochemical and biophysical investigations, this feature renders AOT nearly useless for solution NMR investigations of proteins. Indeed, in our hands, ubiquitin is the only natural protein for which conditions could be found that maintain the native fold structure encapsulated in AOT reverse micelles.

CTAB has also been widely employed for reverse micelle-based studies [11]. This cationic surfactant requires the addition of relatively high concentrations of cosurfactant molecules in order to form stable reverse micelle mixtures. The short-chain primary alcohols are the most common cosurfactants used for CTAB reverse micelle applications. Because these highconcentration cosurfactants contribute somewhat to the overall bulk viscosity of the reverse micelle mixture, low-viscosity short-chain alcohols are more advantageous for promoting fast tumbling of the reverse micelle particle. Shorter-chain alcohols, however, are required in higher concentration than longer-chain alcohols, thus a balance must be struck between high concentrations and a potential degradation of the viscosity. Hexanol provides the best general performance for $\mathrm{CTAB}$ reverse micelle encapsulation of proteins with respect to the overall impact on reverse micelle rotational diffusion. The $\mathrm{CTAB} /$ hexanol mixture has a 
considerably lower charge density at the water-surfactant interface than AOT, producing excellent versatility for encapsulation of a wide range of macromolecules with structural fidelity [18-25]. A practical shortcoming of this reverse micelle system arises from the charged nature of the surfactant-water interface that produces subtle chemical shift perturbations of the encapsulated protein that require reassignment of a minority of amide resonances. Effects on aliphatic resonances are generally small and compare closely to aqueous assignments [22]. Despite this minor limitation, the CTAB/hexanol mixture has been successfully implemented for a wide range of proteins and a broad spectrum of solution NMR techniques as discussed below [21, 23-26].

In order to mitigate complications arising from the high charge density at the watersurfactant interface, nonionic surfactants offer an appealing complement to charged surfactants [18]. $\mathrm{C}_{12} \mathrm{E}_{4}$ is the primary component in a three-surfactant mixture with AOT and DTAB that provides a reduced charge density at the surfactant-water interface, thereby minimizing denaturing effects on the encapsulated proteins and providing the ability to charge-balance the surfactant interface for encapsulation of acidic, neutral, and basic proteins. This surfactant mixture provides excellent versatility for encapsulation of globular proteins and yields close agreement between chemical shifts of encapsulated proteins and those in bulk aqueous solution. Despite these advantages, however, the length of the $\mathrm{C}_{12} \mathrm{E}_{4}$ molecule results in a relatively thick surfactant layer and a larger reverse micelle particle, thereby resulting in significantly slower tumbling. The inclusion of AOT in this mixture also limits its utility in ultra-low viscosity solvents since relatively high pressures are required, which compromises the desired effect (see Figure 2).

Recently, a new surfactant mixture composed of LDAO and 10MAG was developed that offers low charge-density at the water-surfactant interface as well as short contour length of the surfactant layer and amenability to encapsulation in ultra-low viscosity solvents (see Figure 2) [20]. The 10MAG/LDAO surfactant system permits encapsulation of proteins at least as large as $80 \mathrm{kDa}$ with isoelectric points ranging from 4 to 11 . Nucleic acids can also be encapsulated. This surfactant system also provides a net charge-neutral surfactant interface that results in very little perturbation of the NMR spectrum of the encapsulated macromolecule. Importantly, 10MAG/LDAO reverse micelles can be readily prepared in ultra-low viscosity short-chain alkanes providing a significant rotational diffusion advantage.

\section{Sample preparation}

The key to the reverse micelle encapsulation strategy is the nature of the sample. In its simplest form, sample preparation involves mixing of surfactant components in the nonpolar solvent followed by injection of an appropriate volume of protein solution to achieve the desired water content [11]. Due to the substantial dilution of the protein that this direct injection method creates, high concentration aqueous protein solutions $(>2 \mathrm{mM})$ are required to achieve final encapsulated protein concentrations appropriate for efficient collection of NMR spectra (i.e. 100 - $200 \mu \mathrm{M}$ ). In rare cases, protein-free reverse micelle solutions can even be used to simply solubilize dry protein. 
While many proteins are amenable to the high initial concentrations necessary for direct injection, the majority of proteins do not tolerate such conditions. Alternative methods for encapsulation and concentration of the protein in the reverse micelle solution are available. The phase transfer method involves mixing the alkane solution of surfactants with a large volume of dilute aqueous protein solution and subsequently allowing the phases to separate [11]. Under appropriate conditions, the protein will spontaneously partition to achieve reverse micelle protein concentrations appropriate for solution NMR. However, this method suffers from poor control of $W_{0}$, frequently resulting in extremely high water content in the reverse micelle phase that may compromise the tumbling advantages of encapsulation. This problem can, however, be mitigated by the addition of dry surfactants to reduce the $W_{0}$ (i.e. distribute water to reverse micelles not containing a protein molecule) [27].

The phase transfer method is rather unpredictable and cumbersome. To overcome the limitations of the phase transfer and direct injection methods, we have developed a method that allows dilute protein solutions to be used to create solutions of encapsulated protein at sufficient concentrations and water loadings appropriate for NMR [20]. Termed the injection-evaporation method, this approach uses repeated rounds of injection of small volumes of aqueous protein solution followed by partial evaporation. Through this process, dilute protein solutions can be used to produce reverse micelle samples with reasonable concentrations for NMR while offering excellent control of the water content of the system. Generally, solutions of encapsulated proteins can be prepared to concentrations of 0.1 to 0.2 $\mathrm{mM}$. In other words, though solutions of reverse micelles can be made to $\mathrm{mM}$ concentrations, the loading of individual protein molecules is limited to $10-25 \%$. Protein loading is currently the limiting parameter of the reverse micelle NMR strategy and remains a central focus for technical development. The injection-evaporation method shows great promise in this respect.

Historically the principle barrier to the reverse micelle NMR approach has been the identification of appropriate encapsulation conditions (surfactants, concentrations, $W_{0}$. etc.) that provide high structural fidelity with excellent macromolecular tumbling and sufficient long-term sample stability and protein concentration to allow multidimensional NMR studies to be carried forward. As described above, it is hoped that the identification of the 10MAG/LDAO surfactant system and the associated reverse micelle condition screening protocol will provide a general solution to this problem [20]. The tuning of the water content has proven to be a particularly important parameter for identifying appropriate encapsulation conditions. Indeed, it seems that the optimal water content for encapsulated proteins correlates closely with their hydrated radius in free aqueous solution [22]. This suggests that the lowest free energy state of the reverse micelle system tends to favor just enough water to satisfy the protein's hydration layer and therefore provides an ideal balance between protein structural fidelity and optimal tumbling.

Optimization and control of $\mathrm{pH}$ within the reverse micelle interior is also an important factor in preparation of reverse micelle samples. The contributions of titratable surfactant head groups to the effective $\mathrm{pH}$ of the aqueous interior of the reverse micelle have been a controversial and frequently overlooked factor. It must be emphasized that the water core of a reverse micelle that is typically used for NMR studies of encapsulated proteins contains 
only a few molecules of buffer. Thus it cannot be assumed that simply adjusting the $\mathrm{pH}$ of the buffer used to solubilize the protein sets the $\mathrm{pH}$ of the water core. In most cases, it is the character of the surfactants that determines the effective $\mathrm{pH}$. A simple approach for control and measurement of the $\mathrm{pH}$ within the reverse micelle interior has recently been developed and allows facile adjustments in order to set and optimize encapsulation conditions [20,28]

\section{Encapsulation in ultra-low viscosity solvents}

The tumbling advantage offered by reverse micelle encapsulation for large macromolecules fundamentally comes from the low viscosity of the bulk non-polar solvent. Pentane, which is a liquid at standard pressure and temperature, offers a viscosity about $1 / 4$ that of water and is satisfactory for many solution NMR applications. For larger macromolecules, the volume penalty for encapsulation is sufficiently large that there are only a few solvents with low enough viscosity to effectively overcome it. These include the short chain alkanes such as butane, propane and ethane [7, 29], carbon dioxide [16] and xeon [17]. Carbon dioxide has roughly the viscosity of propane but suffers badly from the fact that the $\mathrm{pH}$ of the reverse micelle water core cannot be controlled and is quite acidic [30]. Xeon, with a viscosity approaching that of liquid ethane, has seen far fewer applications, presumably because of a paucity of suitable surfactant systems. The short chain alkanes appear to be the solvents of choice in the context of high-resolution solution NMR of encapsulated macromolecules. Obviously, however, none of these solvents are liquids at STP and elevated pressure is required. Though the short chain alkanes require only moderate pressures to be liquefied at room temperature, experience has shown that considerably higher pressures are required to prepare solutions of encapsulated proteins that are optimal for NMR spectroscopy. For example, samples prepared with the 10MAG/LDAO surfactant system in ethane require pressures on the order of 3500 - 6000 p.s.i (240 - 415 bar), depending on the details of the sample. In most cases, conditions that are identified in liquid pentane require only subtle modification for encapsulation in liquid propane or ethane [20].

Preparation of samples at these pressures requires specialized apparatus [31, 32]. Samples prepared in pentane or other alkane solvents that are liquid at STP can usually be used with standard glass NMR tubes equipped with screw cap seals. Butane samples can be used with heavier walled glass NMR tubes equipped with Teflon needle valves. For propane and ethane, where considerable pressure is required to stabilize solutions of encapsulated proteins, caution requires the use of specialized NMR tubes made from PEEK (for propane) [33] or the more desirable zirconia ceramic (for propane and ethane) [27, 32, 34]. It is important to note that though these pressures require careful consideration, they are well below those required to induce significant structural or dynamical transitions in proteins [35, 36]. The $\mathrm{CTAB} /$ hexanol and 10MAG/LDAO surfactant systems provide excellent encapsulation efficiency in both liquid propane and liquid ethane [22, 31, 34]. Figure 2 shows the theoretical tumbling advantages available through the use of the short chain alkanes. Liquid pentane provides modest tumbling advantages over aqueous solution for proteins of $\sim 40 \mathrm{kDa}$ or larger. Liquid butane, propane or ethane offer the potential for remarkable improvements in rotational diffusion of encapsulated macromolecules. Indeed, in principle, liquid ethane could allow a $100 \mathrm{kDa}$ encapsulated protein to be made to tumble as quickly as a $10 \mathrm{kDa}$ protein in water. It should be noted that the viscosity of ethane is 
particularly sensitive to pressure and this often represents the limiting factor in the use of this solvent for a particular protein system. For example, CTAB/hexanol reverse micelles typically require protein encapsulation pressures of $\sim 3000-5000$ p.s.i $[22,31]$ while the encapsulation pressures for the 10MAG/LDAO system are typically $3500-6000$ p.s.i. [20] producing a viscosity range of $68-90 \mu \mathrm{Pa}$ s. The effective macromolecular tumbling correlation times of encapsulated proteins have been experimentally estimated using the TRACT method [20, 22]. The tumbling advantages achieved are more modest than predicted. These differences likely arise from imperfect optimization, variation of the effective viscosity due to the presence of various co-solvents and co-surfactants and deviation from the assumptions of the prediction model (perfectly spherical geometry, a constant thickness of the protein hydration layer, etc.). Despite these discrepancies, remarkable tumbling advantages can be realized. For example, encapsulation of the 40.8 $\mathrm{kDa}$ maltose-binding protein in $\mathrm{CTAB} / \mathrm{h}$ exanol or 10MAG/LDAO in liquid ethane at $\sim 4500$ p.s.i produces a 2.5-fold improvement in tumbling relative to aqueous solution [20]. Several promising additives that permit lowering of the required encapsulation pressure (and with it the viscosity) have also been identified [31].

\section{Practical considerations}

From a spectroscopic perspective, perhaps the most important difference between a reverse micelle sample and a typical aqueous sample is complexity of the solvent and surfactant mixture. In general, solutions of encapsulated proteins prepared in alkane solvents have a much lower dielectric than an aqueous sample. As a result reverse micelle samples are nonlossy and do not significantly diminish the quality factor of the cryogenically cooled cryoprobe [37]. In practice, this provides a two- to three-fold signal-to-noise advantage, which is particularly important in light of the relatively limited concentration of encapsulated protein solutions that can currently be achieved. Looking forward, the recent demonstration that solutions of reverse micelles seem to enable dynamic nuclear polarization in large-volume liquid samples bodes well for overcoming this concentration limitation in the future [38].

The alkane solvent eliminates the need for the detailed water suppression techniques typically required for aqueous samples. The amount of water in a reverse micelle solution is quite small $(<2.5 \mathrm{M})$, which is generally eliminated by the $\mathrm{X}$-nucleus editing inherent in heteronuclear pulse sequences [1]. For homonuclear ${ }^{1} \mathrm{H}$ multi-dimensional experiments, simple flip-back approaches [39] remove interference from the water resonance. The alkane solvent and surfactants are more challenging, as they are comprised of multiple ${ }^{1} \mathrm{H}$ resonances involved in extensive J-coupling. Deuterated short-chain alkanes are available though 1-2\% residual hydrogen is present in currently available stock. Deuterated solvent also reduces radiation damping [40]. The high concentrations of protonated surfactants provide additional sources of contaminating signals (see Figure 3). Not all surfactants are commercially available in deuterated form. ${ }^{1} \mathrm{H}$ resonances of the surfactants are most effectively eliminated through the use of the gradient-selected quadrature [41], where the $\sqrt{2}$ loss in sensitivity is generally more than compensated by the reduction of $t_{1}$ correlated noise arising from incomplete suppression of surfactant signals. States-TPPI quadrature methods $[42,43]$ can also be employed in combination with WET suppression [44]. 


\section{Validation of the reverse micelle NMR method}

In the context of structural biology and molecular biophysics it makes little sense to undertake studies of proteins and nucleic acids if their native structure cannot be maintained in the reverse micelle. The first protein to be encapsulated and examined using highresolution multi-dimensional NMR methods was the $8.5 \mathrm{kDa}$ model protein ubiquitin [7, 34]. The structure of this protein was solved using AOT reverse micelles dissolved in liquid pentane [19]. The structure of encapsulated ubiquitin was found to be indistinguishable from the x-ray crystallographic [45] and bulk solution NMR structures [46] (Figure 4). The determination of the structure of encapsulated ubiquitin provided an initial proof of principle for the reverse micelle encapsulation strategy. The technology has progressed greatly over the past decade. Whereas encapsulation of ubiquitin in AOT produced sufficient chemical shift (though not structural) perturbations to necessitate de novo assignment, the recently developed 10MAG/LDAO surfactant mixture provides excellent correspondence between the NMR spectra of macromolecules in free aqueous solution and encapsulated. The correspondence of the chemical shifts of amide ${ }^{1} \mathrm{H}$ and ${ }^{15} \mathrm{~N}$ of the $40 \mathrm{kDa}$ arginine kinase encapsulated in 10MAG/LDAO reverse micelles dissolved in liquid ethane is shown in Figure 5.

The development of the various surfactant mixtures described above has permitted globular proteins as large as $103 \mathrm{kDa}$ to be encapsulated (Table 1). Nucleic acids have also been successfully encapsulated [20,47]. In the case of nucleic acids, the confinement of the reverse micelle [47] and reduced rates of hydrogen exchange [20] can significantly improve the spectral quality. The broad range of macromolecules for which the reverse micelle method has been applied reveals the promise of this approach for solution NMR characterization of biological molecules of all kinds.

\section{Access to the full catalog of solution NMR experiments}

\subsection{Assignment of hydrogen resonances and access to the NOE}

A central advantage of the reverse micelle encapsulation strategy is that large proteins retain the spin relaxation properties of smaller proteins through an increased rate of molecular reorientation [7]. In principle this would avoid the need for deuteration and permit the comprehensive assignment of ${ }^{1} \mathrm{H}$ resonances and employment of ${ }^{1} \mathrm{H}-{ }^{1} \mathrm{H}$ NOEs as desired. For example, the $\mathrm{HCC}(\mathrm{CO}) \mathrm{NH}-\mathrm{TOCSY}$ experiments of Montelione and coworkers [48, 49] provide comprehensive side chain correlations resolved on the amide $\mathrm{N}-\mathrm{H}$ but are highly $\mathrm{T}_{2}$ sensitive and their use is generally restricted to smaller proteins. However, the reverse micelle encapsulation strategy overcomes this limitation as is illustrated for the $41 \mathrm{kDa}$ maltose-binding protein $[22,31]$ (Figure 6). Though efforts continue to avoid the extensive use of short range NOEs in the determination of structures of proteins [50], comprehensive access to the NOE greatly increases the probability that a high-resolution model can be obtained. It is also apparent that as larger proteins are made accessible by the reverse micelle method, the spectral complexity becomes correspondingly greater. Traditionally for smaller proteins this is ameliorated through use of three- and four-dimensional NOESY experiments [1]. Four-dimensional ${ }^{15} \mathrm{~N}-\mathrm{HMQC}-\mathrm{NOESY}-{ }^{13} \mathrm{C}-\mathrm{HMQC}$ and ${ }^{13} \mathrm{C}-\mathrm{HMQC}-\mathrm{NOESY}-{ }^{13} \mathrm{C}$ HMQC [51,52] spectra of the $27 \mathrm{kDa}$ membrane-anchored protein recoverin encapsulated 
in $\mathrm{CTAB} /$ hexanol reverse micelles dissolved in liquid pentane illustrate the ability to obtain NOESY spectra on these types of samples (Figure 7). These data were obtained for this protein in its membrane-anchored state without the need for high pressure, ultra-low viscosity solvents. It should be noted that the required collection times for these data sets was comparable to that required for collection of such data on a typical aqueous protein of comparable size.

\subsection{Paramagnetic relaxation enhancement}

Paramagnetic relaxation enhancement (PRE) effects have become a widely used to obtain long-distance restraints and dynamical information [53, 54]. PRE data are readily obtained for encapsulated proteins using the same methods as applied in aqueous solution. Figure 8 illustrates attenuation of amide hydrogen cross peak intensity in a ${ }^{15} \mathrm{~N}-\mathrm{HSQC}$ spectrum in the presence of oxidized (paramagnetic) MTSL versus reduced (diamagnetic) MTSL attached to residue 57 of a double mutant (S57C, C55A) of the $19 \mathrm{kDa}$ protein flavodoxin in 10MAG/LDAO reverse micelles dissolved in liquid pentane [38]. These relaxation enhancements are also mapped to a cartoon of the flavodoxin structure, illustrating the expected distance relationship between the site of the probe and the broadened amide sites.

\subsection{Residual dipolar couplings}

Residual dipolar couplings (RDCs) are not only critical to obtaining high quality structural models [55] but are also rich in motional information [56]. A variety of mechanisms are available in aqueous solution to induce the partial alignment necessary to reintroduce dipolar couplings. As mentioned above, the phase diagram of reverse micelle surfactants is complex and contains regions where small reverse micelles suitable for NMR and liquid crystalline components co-exist $[12,57]$. In addition, there are regions of the phase diagram for proteincontaining reverse micelles where the particles are non-spherical and can have an inherent anisotropic magnetic susceptibility [26]. These various conditions can be populated through manipulation of surfactant concentrations and ratios and can result in partial alignment. Sufficient partial alignment to produce measureable RDCs has been demonstrated for a number of small proteins [26]. An example is shown in Figure 9.

\section{Additional applications}

\subsection{Ligand binding}

In addition to providing access to the standard solution NMR experiments for determination of structure and dynamics of macromolecules, reverse micelle samples are also amenable to a wide range of biochemical and biophysical characterization methods typically applied in aqueous solution. Small molecule binding studies can be routinely carried out with encapsulated macromolecules. For example, the membrane-associated HIV-1 matrix protein was encapsulated in its lipid-extruded form and anchored to the reverse micelle surfactant layer [25]. In this context, the reverse micelle provided a useful membrane mimetic system that allowed the binding of the lipid ligand $\mathrm{PI}(4,5) \mathrm{P}_{2}$ to be monitored [25] (Figure 10). Similar experiments have also been used to characterize the sequestration of the myristoyl group of the peripheral membrane protein recoverin [25]. 
Integral membrane proteins have also been encapsulated and examined using high resolution NMR [23, 24, 58]. In a somewhat demanding case, the reverse micelle provided sufficient structural support to encapsulate the $54 \mathrm{kDa}$ potassium channel KcsA in its functional form [23]. Functional competence was demonstrated by the selective binding of potassium over an excess of sodium, which was detected by chemical shift perturbations induced by titration with potassium [23] (Figure 10). The potassium binding properties and the localization of chemical shift changes upon potassium binding closely mirrored those measured previously in micelles in aqueous solution [59] where tumbling of the protein is much more problematic.

\subsection{Protein biophysics}

The nanoscale water core of the reverse micelles has a number of characteristics that can be utilized in studies of macromolecular structure and biophysics. For example, the small volume of the water core can serve as a "confined space" that promotes protein folding by disfavoring extensive (partially) unfolded states [60]. Similar effects can be used to stabilize oligomers [61]. The small scale also suppresses the freezing point of the water core such that certain reverse micelle solutions are stable to -20 to $-30{ }^{\circ} \mathrm{C}$. This permitted the cold denaturation of ubiquitin to be characterized in detail without the need for destabilization through application of pressure or addition of denaturants [62, 63]. The dynamics of water [64] and acid-base catalysis [65] are considerably slowed in the core of small reverse micelles relative to bulk aqueous solution.

The slowed motion of water in the hydration layer of the encapsulated protein permits extensive site-resolved detection of the interaction of water with the surface of the protein via NOE/ROE ratios [66]. The suppression of hydrogen exchange chemistry largely eliminates the artifacts that make this approach difficult in bulk solution [67, 68]. In the first application of this strategy, slow hydration water was associated with regions of the ubiquitin surface that binds other proteins (Figure 11). This suggests that protein hydration may be optimized to promote binding by manipulation of the hydrophobic effect i.e. by maximizing the entropy gain of surface water displaced by binding [69]. The ability to faithfully detect the interaction between water and protein also allowed the mechanism of pressure-induced protein unfolding to be examined. Simulations had suggested that water penetrates the core of ubiquitin at high-pressure, promoting unfolding [70]. Reverse micelle samples are reasonably pressure resistant, which allowed this to be examined experimentally. Encapsulated ubiquitin was shown to maintain structural integrity up to 2.5 kbar (Figure 10) but no interior water was detected [71]. These are but a few illustrations of the range of unique applications of reverse micelle NMR in protein biophysics.

\section{Summary}

Reverse micelle encapsulation provides a range of advantages for investigation of structural and biophysical characterization of macromolecules using solution NMR methods. A primary motivation for using this approach is the ability to make the rotational correlation time of the encapsulated macromolecule shorter than it is free in aqueous solution by simply using a low viscosity solvent. A variety of surfactant systems are available for robust encapsulation that preserves the native structure of the protein or nucleic acid. The recently 
developed 10MAG/LDAO surfactant system is broadly useful and is able to encapsulate macromolecules with quite variable physical properties without the need for extensive optimization. In addition to classic structure determination, the reverse micelle NMR systems offer a range of benefits in biophysical studies of proteins and nucleic acids such as hydration, temperature and pressure dependent phenomena, ligand binding, confined space effects and so on. The recent observation of substantial nitroxide-mediated dynamic nuclear polarization of the reverse micelle water core encourages the development of the reverse micelle NMR method as a generally applicable approach [38].

\section{Acknowledgments}

This work was supported by NSF grant MCB-115803 and NIH grants GM085120 and GM107829.

\section{References}

[1]. Rule, GS.; Hitchens, TK. Fundamentals of Protein NMR Spectroscopy. Springer; Dordrecht, The Netherlands: 2006.

[2]. Gardner KH, Kay LE. The use of H-2, C-13, N-15 multidimensional NMR to study the structure and dynamics of proteins. Annu. Rev. Biophys. Biomol. Struct. 1998; 27:357-406. [PubMed: 9646872]

[3]. Goto NK, Kay LE. New developments in isotope labeling strategies for protein solution NMR spectroscopy. Current Opinion in Structural Biology. 2000; 10:585-592. [PubMed: 11042458]

[4]. Tugarinov V, Kanelis V, Kay LE. Isotope labeling strategies for the study of high-molecularweight proteins by solution NMR spectroscopy. Nature Protocols. 2006; 1:749-754.

[5]. Pervushin K, Riek R, Wider G, Wuthrich K. Attenuated T-2 relaxation by mutual cancellation of dipole-dipole coupling and chemical shift anisotropy indicates an avenue to NMR structures of very large biological macromolecules in solution. Proc. Nat. Acad. Sci. USA. 1997; 94:1236612371. [PubMed: 9356455]

[6]. Tugarinov V, Hwang PM, Kay LE. Nuclear magnetic resonance spectroscopy of high-molecularweight proteins. Annu. Rev. Biochem. 2004; 73:107-146. [PubMed: 15189138]

[7]. Wand AJ, Ehrhardt MR, Flynn PF. High-resolution NMR of encapsulated proteins dissolved in low-viscosity fluids. Proc. Natl. Acad. Sci. U. S. A. 1998; 95:15299-15302. [PubMed: 9860963]

[8]. Lipari G, Szabo A. Model-free approach to the interpretation of nuclear magnetic-resonance relaxation in macromolecules. 1. Theory and range of validity. J. Am. Chem. Soc. 1982; 104:4546-4559.

[9]. Klibanov AM. Enzymatic catalysis in anhydrous organic solvents. Trends Biochem. Sci. 1989; 14:141-144. [PubMed: 2658221]

[10]. Klibanov AM. Improving enzymes by using them in organic solvents. Nature. 2001; 409:241246. [PubMed: 11196652]

[11]. Luisi PL, Giomini M, Pileni MP, Robinson BH. Reverse micelles as hosts for proteins and small molecules. Biochim. Biophys. Acta. 1988; 947:209-246. [PubMed: 3278740]

[12]. De TK, Maitra A. Solution behavior of Aerosol Ot in nonpolar-solvents. Adv. Colloid Interface Sci. 1995; 59:95-193.

[13]. Tingey JM, Fulton JL, Matson DW, Smith RD. Micellar and biocontinuous microemulsions formed in both near-critical and supercritical propane with didodecyldimethylammonium bromide and water. J. Phys. Chem. 1991; 95:1445-1448.

[14]. De Marco, a.; Zetta, L.; Menegatti, E.; Luisi, PL. 1H-NMR of reverse micelles. II: Conformational studies of peptides and proteins in the AOT/water/isooctane system. J. Biochem. Bioph. Methods. 1986; 12:335-47.

[15]. Thompson KF, Gierasch LM. Conformation of a peptide solubilizate in a reversed micelle water pool. J. Am. Chem. Soc. 1984; 106:3648-3652. 
[16]. Gaemers S, Elsevier CJ, Bax A. NMR of biomolecules in low viscosity, liquid CO2. Chem. Phys. Lett. 1999; 301:138-144.

[17]. Meier M, Fink A, Brunner E. Reverse micelles dissolved in supercritical Xenon: An NMR spectroscopic study. J. Phys. Chem. B. 2005; 109:3494-3498. [PubMed: 16851384]

[18]. Peterson RW, Pometun MS, Shi Z, Wand AJ. Novel surfactant mixtures for NMR spectroscopy of encapsulated proteins dissolved in low-viscosity fluids. Protein Sci. 2005; 14:2919-21. [PubMed: 16199658]

[19]. Babu CR, Flynn PF, Wand AJ. Validation of protein structure from preparations of encapsulated proteins dissolved in low viscosity fluids. J. Am. Chem. Soc. 2001; 123:2691-2692. [PubMed: 11456950]

[20]. Dodevski I, Nucci NV, Sidhu GK, Valentine KG, Wand AJ. Optimized reverse micelle surfactant system for high-resolution NMR spectroscopy of encapsulated proteins dissolved in lowviscosity fluids. J. Am. Chem. Soc. 2013 submitted.

[21]. Lefebvre BG, Liu W, Peterson RW, Valentine KG, Wand AJ. NMR spectroscopy of proteins encapsulated in a positively charged surfactant. Journal of magnetic resonance (San Diego, Calif. : 1997). 2005; 175:158-62.

[22]. Nucci NV, Marques BS, Bedard S, Dogan J, Gledhill JM Jr. Moorman VR, Peterson RW, Valentine KG, Wand AL, Wand AJ. Optimization of NMR spectroscopy of encapsulated proteins dissolved in low viscosity fluids. J. Biomol. NMR. 2011; 50:421-430. [PubMed: 21748265]

[23]. Kielec JM, Valentine KG, Babu CR, Wand AJ. Reverse micelles in integral membrane protein structural biology by solution NMR spectroscopy. Structure. 2009; 17:345-51. [PubMed: 19278649]

[24]. Kielec JM, Valentine KG, Wand AJ. A method for solution NMR structural studies of large integral membrane proteins: reverse micelle encapsulation. Biochim. Biophys. Acta. 2010; 1798:150-60. [PubMed: 19665988]

[25]. Valentine KG, Peterson RW, Saad JS, Summers MF, Xu X, Ames JB, Wand AJ. Reverse micelle encapsulation of membrane-anchored proteins for solution NMR studies. Structure (London, England : 1993). 2010; 18:9-16.

[26]. Valentine KG, Pometun MS, Kielec JM, Baigelman RE, Staub JK, Owens KL, Wand AJ. Magnetic susceptibility-induced alignment of proteins in reverse micelles. J. Am. Chem. Soc. 2006; 128:15930-15931. [PubMed: 17165694]

[27]. Babu CR, Flynn PF, Wand AJ. Preparation, characterization, and NMR spectroscopy of encapsulated proteins dissolved in low viscosity fluids. J. Biomol. NMR. 2003; 25:313-323. [PubMed: 12766393]

[28]. Marques BS, Nucci NV, Dodevski I, Wang KWC, Athanasoula EA, Jorge C, Wand AJ. Measurement and control of $\mathrm{pH}$ in the aqueous interior of reverse micelles. J. Phys. Chem. B. 2013 submitted.

[29]. Peterson RW, Lefebvre BG, Wand AJ. High-resolution NMR studies of encapsulated proteins in liquid ethane. J. Am. Chem. Soc. 2005; 127:10176-10177. [PubMed: 16028922]

[30]. Niemeyer ED, Bright FV. The $\mathrm{pH}$ within PFPE reverse micelles formed in supercritical CO2. J. Phys. Chem. B. 1998; 102:1474-1478.

[31]. Peterson RW, Nucci NV, Wand AJ. Modification of encapsulation pressure of reverse micelles in liquid ethane. J. Magn. Reson. 2011; 212:229-33. [PubMed: 21764613]

[32]. Peterson RW, Wand AJ. Self-contained high-pressure cell, apparatus, and procedure for the preparation of encapsulated proteins dissolved in low viscosity fluids for nuclear magnetic resonance spectroscopy. Rev. Sci. Instrum. 2005; 76

[33]. Flynn PF, Milton MJ, Babu CR, Wand AJ. A simple and effective NMR cell for studies of encapsulated proteins dissolved in low viscosity solvents. J. Biomol. NMR. 2002; 23:311-316. [PubMed: 12398351]

[34]. Ehrhardt MR, Flynn PF, Wand AJ. Preparation of encapsulated proteins dissolved in low viscosity fluids. J. Biomol. NMR. 1999; 14:75-78. [PubMed: 10382308]

[35]. Akasaka K. Probing conformational fluctuation of proteins by pressure perturbation. Chem. Rev. 2006; 106:1814-1835. [PubMed: 16683756] 
[36]. Royer CA. Revisiting volume changes in pressure-induced protein unfolding. Biochim. Biophys. Acta-Protein Struct. Mol. Enzym. 2002; 1595:201-209.

[37]. Flynn PF, Mattiello DL, Hill HDW, Wand AJ. Optimal use of cryogenic probe technology in NMR studies of proteins. J. Am. Chem. Soc. 2000; 122:4823-4824.

[38]. Valentine KG, Mathies G, Bédard S, Nucci NV, Dodevski I, Stetz MA, Thach VC, Griffin RG, Wand AJ. Reverse micelles as a platform for dynamic nuclear polarization in solution NMR of proteins. J. Am. Chem. Soc. 2013 submitted.

[39]. Grzesiek S, Bax A. The importance of not saturating H2O in protein NMR. Application to sensitivity enhancement and NOE measurements. J. Am. Chem. Soc. 1993:12593, 12594.

[40]. Krishnan VV, Murali N. Radiation damping in modern NMR experiments: progress and challenges. Prog. Nucl. Magn. Reson. Spectrosc. 2013; 68:41-57. [PubMed: 23398972]

[41]. Kay LE, Nicholson LK, Delaglio F, Bax A, Torchia DA. Pulse sequences for removal of the effects of cross correlation between dipolar and chemical-shift anisotropy relaxation mechanisms on the measurement of heteronuclear T1 and T2 values in proteins. J. Magn. Reson. 1992; 97:359-375.

[42]. Marion D, Ikura M, Tschudin R, Bax A. Rapid recording of 2D NMR spectra without phase cycling. Application to the study of hydrogen exchange in proteins. J. Magn. Reson. 1989; 85:393-399.

[43]. States DJ, Haberkorn RA, Ruben DJ. A two-dimensional nuclear Overhauser experiment with pure absorption phase in 4 quadrants. J. Magn. Reson. 1982; 48:286-292.

[44]. Smallcombe SH, Patt SL, Keifer PA. WET solvent suppression and its applications to LC NMR and high-resolution NMR spectroscopy. J. Magn. Reson. 1995; 117:295-303. Ser A.

[45]. Vijaykumar S, Bugg CE, Cook WJ. Structure of ubiquitin refined at 1.8 A resolution. J. Mol. Biol. 1987; 194:531-544. [PubMed: 3041007]

[46]. Cornilescu G, Marquardt JL, Ottiger M, Bax A. Validation of protein structure from anisotropic carbonyl chemical shifts in a dilute liquid crystalline phase. J. Am. Chem. Soc. 1998; 120:68366837.

[47]. Workman H, Flynn PF. Stabilization of RNA oligomers through reverse micelle encapsulation. J. Am. Chem. Soc. 2009; 131:3806. [PubMed: 19292481]

[48]. Lyons BA, Montelione GT. An HCCNH triple-resonance experiment using C-13 isotropic mixing for correlating Backbone amide and side-chain aliphatic resonances in isotopically enriched proteins. J. Magn. Reson. 1993; 101:206-209. Ser B.

[49]. Montelione GT, Lyons BA, Emerson SD, Tashiro M. An efficient triple resonance experiment using C-13 isotropic mixing for determining sequence-specific resonance assignments of isotopically-enriched proteins. J. Am. Chem. Soc. 1992; 114:10974-10975.

[50]. Lange OF, Rossi P, Sgourakis NG, Song YF, Lee HW, Aramini JM, Ertekin A, Xiao R, Acton TB, Montelione GT, Baker D. Determination of solution structures of proteins up to $40 \mathrm{kDa}$ using CS-Rosetta with sparse NMR data from deuterated samples. Proc. Natl. Acad. Sci. U. S. A. 2012; 109:10873-10878. [PubMed: 22733734]

[51]. Kay LE, Clore GM, Bax A, Gronenborn AM. 4-dimensional heteronuclear triple-resonance NMR spectroscopy of interleukin 1-beta in solution. Science. 1990; 249:411-414. [PubMed: 2377896]

[52]. Diercks T, Coles M, Kessler H. An efficient strategy for assignment of cross-peaks in 3D heteronuclear NOESY experiments. J. Biomol. NMR. 1999; 15:177-180. [PubMed: 20872110]

[53]. Jeschke G. Conformational dynamics and distribution of nitroxide spin labels. Prog. Nucl. Magn. Reson. Spectrosc. 2013; 72:42-60. [PubMed: 23731861]

[54]. Keizers PM, Ubbink M. Paramagnetic tagging for protein structure and dynamics analysis. Prog. Nucl. Magn. Reson. Spectrosc. 2011; 58:88-96. [PubMed: 21241885]

[55]. Bax A, Grishaev A. Weak alignment NMR: a hawk-eyed view of biomolecular structure. Curr Opin Struct Biol. 2005; 15:563-70. [PubMed: 16140525]

[56]. Bouvignies G, Markwick PRL, Blackledge M. Simultaneous definition of high resolution protein structure and backbone conformational dynamics using NMR residual dipolar couplings. Chemphyschem. 2007; 8:1901-9. [PubMed: 17654630] 
[57]. Palazzo G, Carbone L, Colafemmina G, Angelico R, Chimica D, Sapienza L, Moro PA. The role of the cosurfactant in the CTAB/water/n-pentanol/n-hexane system: Pentanol effect on the phase equilibria and mesophase structure. PCCP. 2004; 6:1423-1429.

[58]. Van Horn WD, Ogilvie ME, Flynn PF. Use of reverse micelles in membrane protein structural biology. J. Biomol. NMR. 2008; 40:203-211. [PubMed: 18297402]

[59]. Chill JH, Louis JM, Miller C, Bax A. NMR study of the tetrameric KcsA potassium channel in detergent micelles. Protein Sci. 2006; 15:684-698. [PubMed: 16522799]

[60]. Peterson RW, Anbalagan K, Tommos C, Wand AJ. Forced folding and structural analysis of metastable proteins. J. Am. Chem. Soc. 2004; 126:9498-9. [PubMed: 15291527]

[61]. Van Horn WD, Ogilvie ME, Flynn PF. Reverse micelle encapsulation as a model for intracellular crowding. J. Am. Chem. Soc. 2009; 131:8030-8039. [PubMed: 19469539]

[62]. Babu CR, Hilser VJ, Wand AJ. Direct access to the cooperative substructure of protein and the protein ensemble via cold denaturation. Nature Struct.Mol. Biol. 2004; 11:352-357. [PubMed: 14990997]

[63]. Pometun MS, Peterson RW, Babu CR, Wand AJ. Cold denaturation of encapsulated ubiquitin. J. Am. Chem. Soc. 2006; 128:10652-10653. [PubMed: 16910639]

[64]. Levinger NE, Swafford LA. Ultrafast dynamics in reverse micelles. Annu. Rev. Phys. Chem. 2009; 60:385-406. [PubMed: 18999990]

[65]. Nucci NV, Pometun MS, Wand AJ. Site-resolved measurement of water-protein interactions by solution NMR. Nat Struct Mol Biol. 2011; 18:245-249. [PubMed: 21196937]

[66]. Otting G, Liepinsh E, Wuthrich K. Protein hydration in aqueous solution. Science. 1991; 254:974-80. [PubMed: 1948083]

[67]. Halle B. Cross-relaxation between macromolecular and solvent spins: The role of long-range dipole couplings. The Journal of Chemical Physics. 2003; 119:12372.

[68]. Halle B. Protein hydration dynamics in solution: a critical survey. Philos. Trans. R. Soc. London. 2004; 359:1207-1224. Ser. B. [PubMed: 15306377]

[69]. Nucci NV, Pometun MS, Wand AJ. Mapping the hydration dynamics of ubiquitin. J. Am. Chem. Soc. 2011; 133:12326-12329. [PubMed: 21761828]

[70]. Day R, Garcia AE. Water penetration in the low and high pressure native states of ubiquitin. Proteins. 2008; 70:1175-1184. [PubMed: 17847086]

[71]. Fu Y, Kasinath V, Moorman VR, Nucci NV, Hilser VJ, Wand AJ. Coupled motion in proteins revealed by pressure perturbation. J. Am. Chem. Soc. 2012; 134:8543-50. [PubMed: 22452540]

[72]. Xu YQ, Zheng Y, Fan JS, Yang DW. A new strategy for structure determination of large proteins in solution without deuteration. Nature Methods. 2006; 3:931-937. [PubMed: 17060917]

[73]. DeLano, WL. The PyMOL molecular graphics system. DeLano Scientific LLC; Palo Alto, California, USA: 2009.

[74]. Tinoco I, Sauer K, Wang J. Physical Chemistry: Principles and Applications in Biological Sciences. 1995

[75]. Lemmon, EW.; McLinden, MO.; Friend, DG. Thermophysical Properties of Fluid Systems. In: Linstrom, PJ.; Mallard, WG., editors. NIST Chemistry WebBook, NIST Standard Reference Database Number 69. National Institute of Standards and Technology; Gaithersburg, MD: 2013.

[76]. Muhandiram DR, Xu GY, Kay LE. An enhanced-sensitivity pure absorption gradient 4D N-15, C-13-edited NOESY experiment. J. Biomol. NMR. 1993; 3:463-470.

[77]. Vuister GW, Clore GM, Gronenborn AM, Powers R, Garrett DS, Tschudin R, Bax A. Increased resolution and improved spectral quality in 4-dimensional C-13/C-13-separated HMQC-NOESYHMQC spectra using pulsed-field gradients. J. Magn. Reson. 1993; 101:210-213. Ser B.

[78]. Rao ST, Shaffie F, Yu C, Satyshur KA, Stockman BJ, Markley JL, Sundaralingam M. Structure of the oxidized long-chain flavodoxin from Anabaena-7120 at 2-Angstrom resolution. Protein Sci. 1992; 1:1413-1427. [PubMed: 1303762]

[79]. Massiah MA, Starich MR, Paschall C, Summers MF, Christensen AM, Sundquist WI. 3dimensional structure of the human-immunodeficiency-virus type-1 matrix protein. J. Mol. Biol. 1994; 244:198-223. [PubMed: 7966331] 


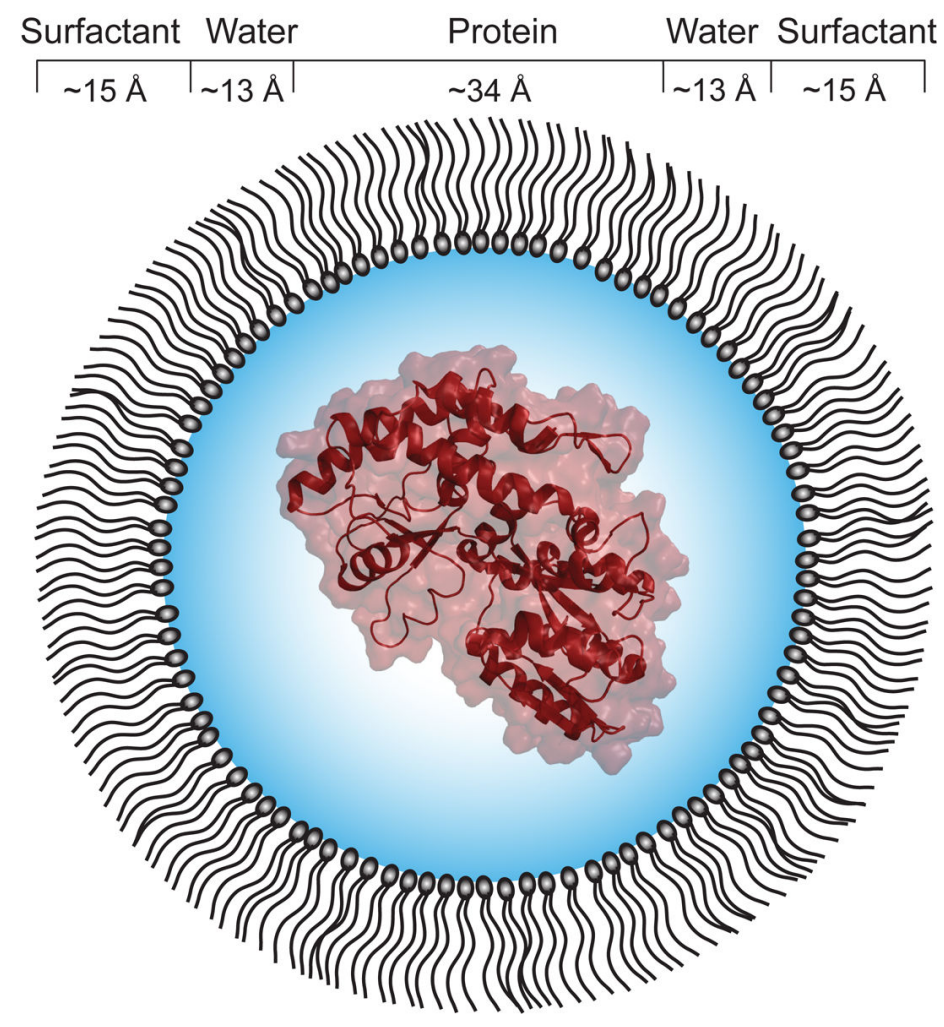

Figure 1.

Schematic of a reverse micelle encapsulating a protein. Maltose-binding protein is shown in cartoon representation (PDB ID 2H25) [72] encapsulated within a reverse micelle. Drawn to scale. The diameter of the protein was measured using Pymol [73]. The diameter of the water core is based on measurements of MBP tumbling in reverse micelles composed of $\mathrm{CTAB} /$ hexanol in various solvents [22]. The thickness of the surfactant layer is based on estimates for CTAB protein-free reverse micelle systems [57]. A reverse micelle under these conditions contains approximately 200 surfactant molecules and $~ 3000$ water molecules. 


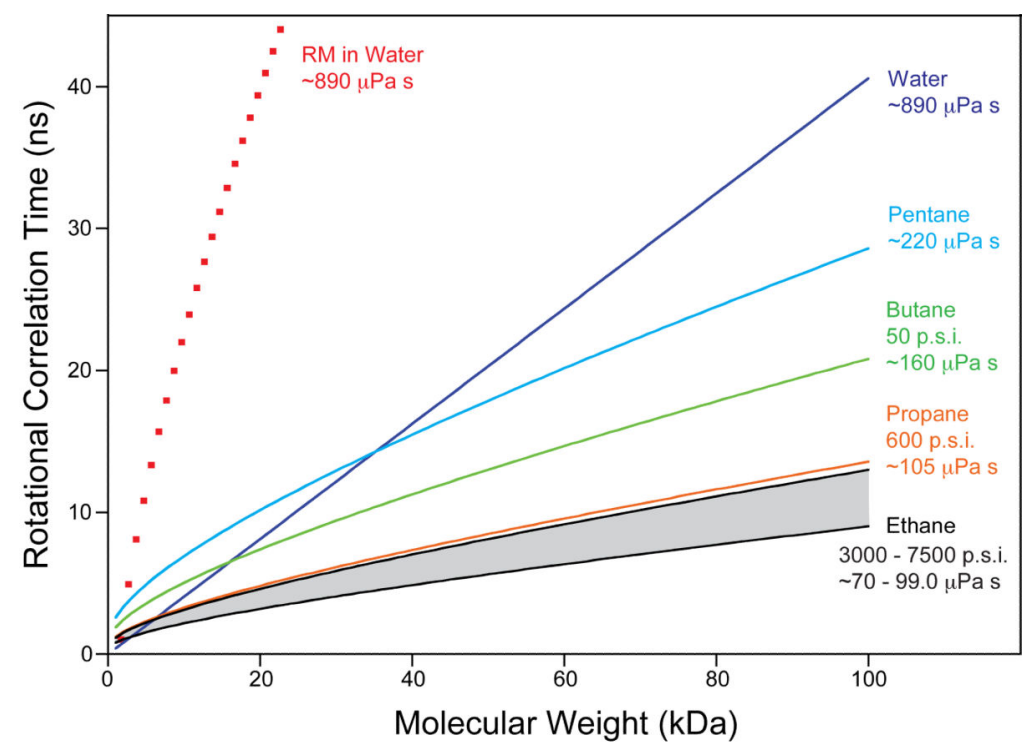

Figure 2.

Calculated effective isotropic rotational correlation time $\left(\tau_{m}\right)$ for encapsulated proteins prepared in various nonpolar solvents. Based on a spherical particle whose size is determined by the hydrated radius of the protein plus the thickness of the surfactant layer [22]. The hydrated radius was a spherical protein of average density and average hydration [74]. Viscosities were obtained from the US National Institute of Standards and Technology [75]. The viscosity of ethane is relatively pressure sensitive and viscosity over the range of pressures typically used is shown in gray. While specific conditions will produce some variation from these predictions, these types of estimations agree well with experimental determinations for the CTAB/hexanol and 10MAG/LDAO reverse micelle systems [20, 22]. 


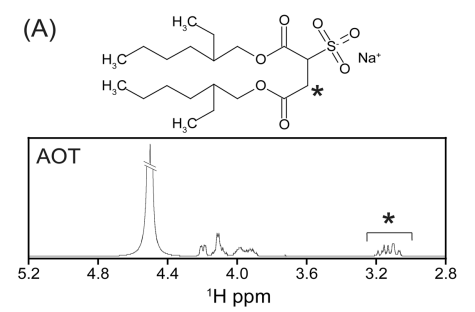

(B)

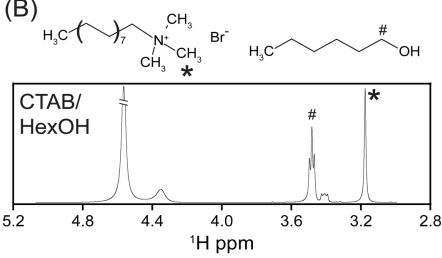

(C)

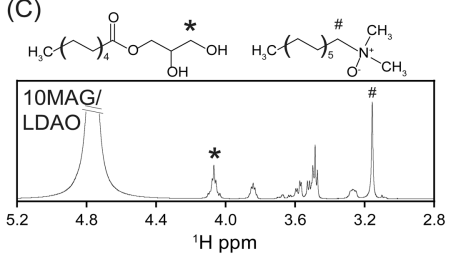

(D)

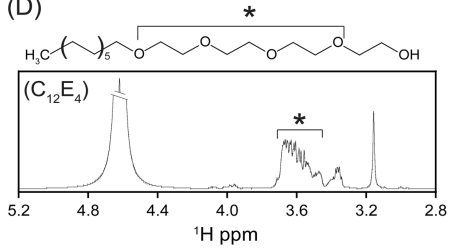

Figure 3.

Structures and ${ }^{1} \mathrm{H}$ spectra of select reverse micelle surfactant systems. One-dimensional ${ }^{1} \mathrm{H}$ spectra are shown for each of four reverse micelle surfactant mixtures at $W_{O}$ of 15 . (A) 75 $\mathrm{mM}$ bis-2-ethylhexylsulfosuccinate (AOT). (B) $75 \mathrm{mM}$ cetyltrimethylammonium bromide (CTAB) with $450 \mathrm{mM}$ hexanol (HexOH) as cosurfactant. (C) $105 \mathrm{mM}$ tetraethylene glycol monodecylether $\left(\mathrm{C}_{12} \mathrm{E}_{4}\right), 30 \mathrm{mM}$ AOT, $15 \mathrm{mM}$ dodecyltrimethylammonium bromide

(DTAB). (D) $52.5 \mathrm{mM}$ decyl-1-rac-glycerol (10MAG), $22.5 \mathrm{mM}$ lauryldimethylamine-Noxide (LDAO). Distinct ${ }^{1} \mathrm{H}$ sites for each surfactant are indicated by $*$ or ${ }^{\#}$ on the chemical structure and on the spectra at the characteristic resonance. In each spectrum, the singlet at far left is the water signal. No solvent suppression methods were employed in the collection or processing of these data. All samples are dissolved in $d-8(98 \%)$ pentane (Cambridge Isotopes, Tewksbury, MA). 


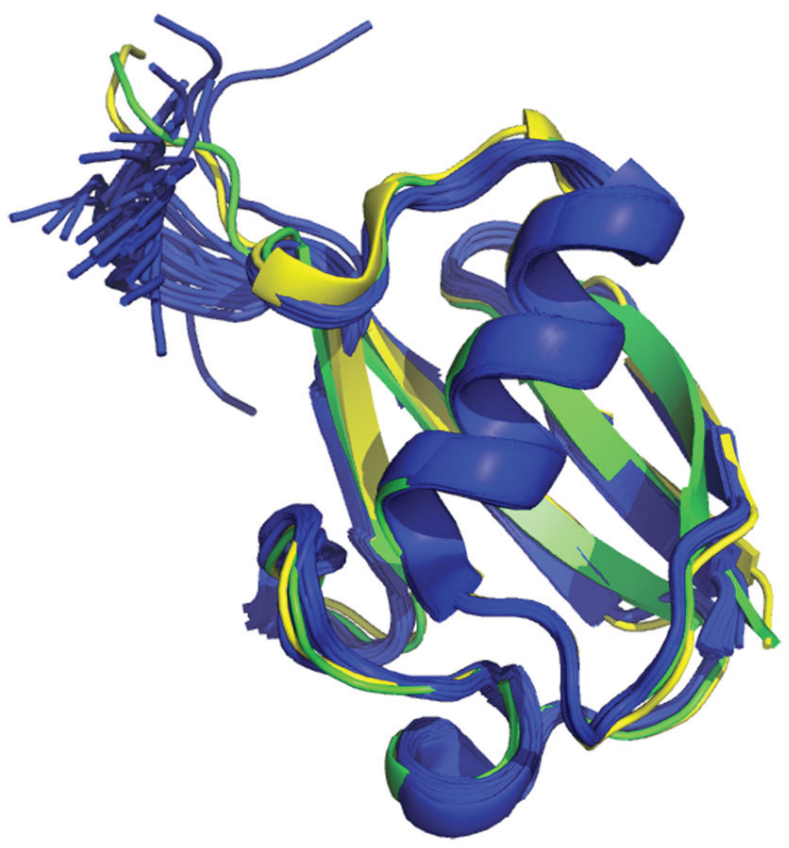

Figure 4.

Aligned ensemble of structures of encapsulated ubiquitin (1G6J) (blue) determined by NMR [19]. Also shown is the crystal structure of ubiquitin (1UBQ) [45] (green) and the lowest energy conformer of the ensemble determined for the protein in free aqueous solution (1D3Z) (yellow) [46]. The structures are statistically indistinguishable. 
(A)

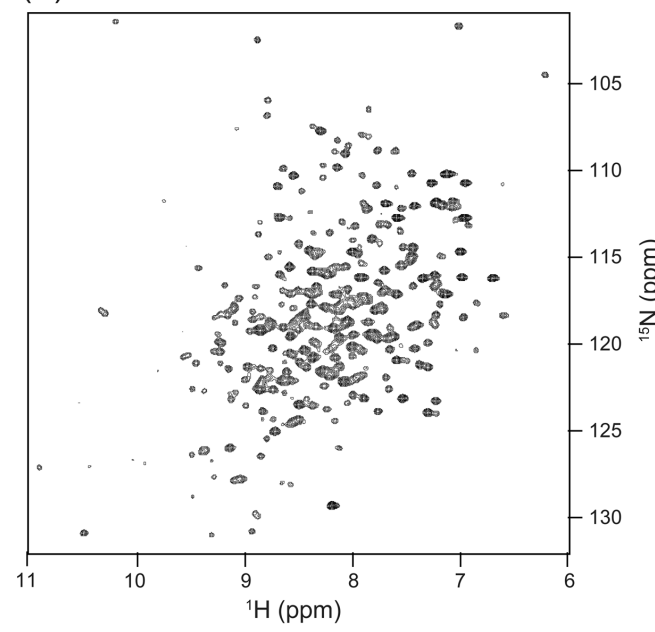

(B)

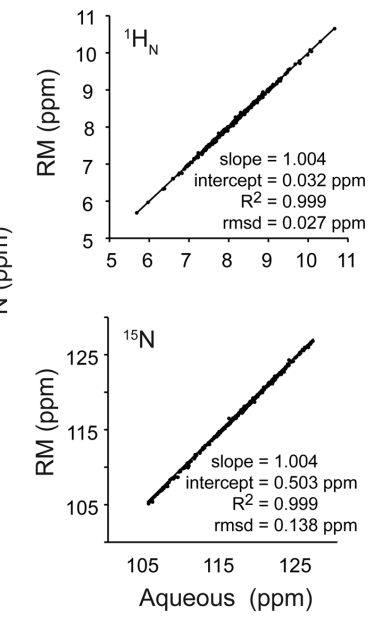

Figure 5.

(A) ${ }^{15} \mathrm{~N}$-HSQC spectrum of arginine kinase in $10 \mathrm{MAG} / \mathrm{LDAO}$ reverse micelles dissolved in liquid ethane [20]. (B) Comparison of amide ${ }^{1} \mathrm{H}$ and ${ }^{15} \mathrm{~N}$ chemical shifts the protein enapsualted in 10MAG/LDAO reverse micelles versus those in aqueous solution. 


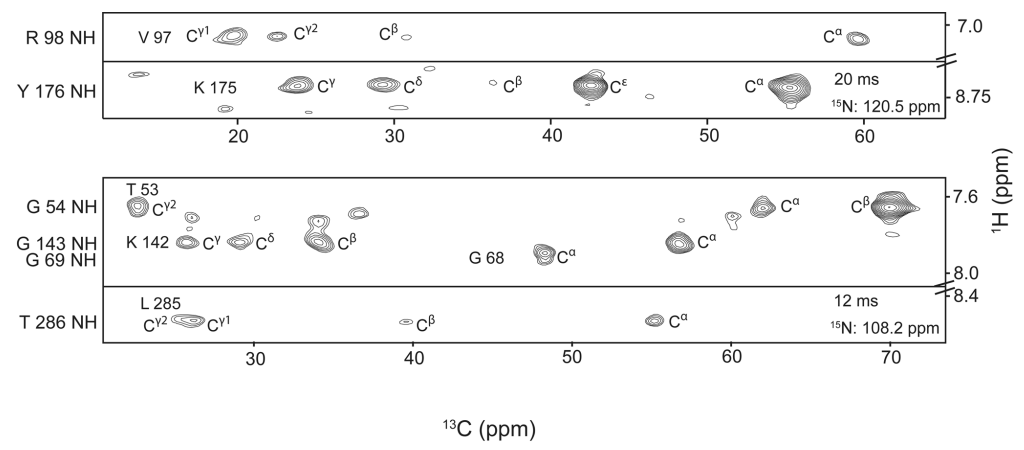

Figure 6.

Planes of a (H)C(CO)NNH TOCSY experiment [48, 49] from uniformly ${ }^{15} \mathrm{~N},{ }^{13} \mathrm{C}$-labeled maltose-binding protein encapsulated in $\mathrm{CTAB} /$ hexanol reverse micelles in liquid ethane. Figure modified from [31]. Data were collected at $600 \mathrm{MHz}$ on a Bruker Avance-III TXI cryoprobe at $20^{\circ} \mathrm{C}$. TOCSY mixing times and indirect ${ }^{15} \mathrm{~N}$ resonances for the pictured data are indicated. 
(A)

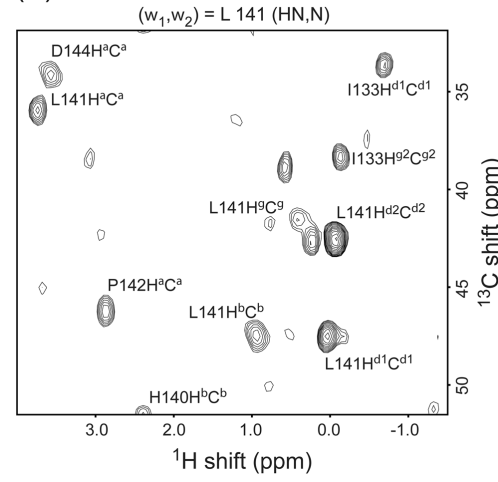

(B)

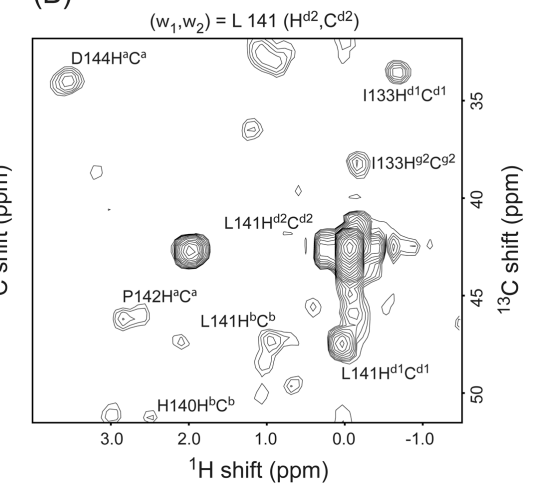

Figure 7.

Planes of four-dimensional NOESY spectra of myristoylated recoverin in reverse micelles. (A) An indirect ${ }^{1} \mathrm{H},{ }^{13} \mathrm{C}$ plane at $\omega_{1}=7.18 \mathrm{ppm}{ }^{1} \mathrm{H}$ and $\omega_{2}=121.7 \mathrm{ppm}{ }^{15} \mathrm{~N}$ of the $4 \mathrm{D}{ }^{13} \mathrm{C}$ HSQC-NOESY_- ${ }^{15} \mathrm{~N}-\mathrm{HSQC}$ spectrum [76] of $225 \mu \mathrm{M}$ uniform ${ }^{15} \mathrm{~N}-{ }^{13} \mathrm{C}$ labeled myristoylated revoverin in $75 \mathrm{mM} \mathrm{CTAB}, 400 \mathrm{mM}$ hexanol in pentane. The ${ }^{1} \mathrm{H}$ acquisition dimension $\omega_{1}$ is collected with 512 complex points, 16 complex points in the $\omega_{2}{ }^{15} \mathrm{~N}$ dimension, 32 complex points in the $\omega_{3}{ }^{1} \mathrm{H}$ dimension and 16 complex points in the $\omega_{4}{ }^{13} \mathrm{C}$ dimension. A sweep width of 20 PPM was used in the $\omega_{4}{ }^{13} \mathrm{C}$ dimension, heavily folded for optimal resolution with minimum overlap. The NOESY mixing time was $90 \mathrm{~ms}$. The total data collection time was 164 hours. The 4D spectrum was processed using Felix processing software (Molecular Simulations) including forward linear prediction of $\sim 20 \%$ of the ${ }^{13} \mathrm{C} \omega_{2}$ complex points. (B) An indirect ${ }^{1} \mathrm{H},{ }^{13} \mathrm{C}$ plane at $\omega_{1}=0.92 \mathrm{ppm}{ }^{1} \mathrm{H}$ and $\omega_{2}=42.5 \mathrm{ppm}{ }^{13} \mathrm{C}$ of the four-dimensional ${ }^{13} \mathrm{C}-\mathrm{HMQC}-\mathrm{NOESY}-{ }^{13} \mathrm{C}-\mathrm{HMQC}$ spectrum [77] of the above sample. The acquisition dimension $\omega_{1}$ was collected with 512 complex points, 32 complex points in the $\omega_{2}{ }^{13} \mathrm{C}$ dimension, 26 complex points in the $\omega_{3}{ }^{1} \mathrm{H}$ dimension and 20 complex points in the $\omega_{4}{ }^{13} \mathrm{C}$ dimension. A sweep width of $20 \mathrm{PPM}$ was used in both the $\omega_{2}$ and $\omega_{4}{ }^{13} \mathrm{C}$ dimensions, folded for optimal resolution. The NOESY mixing time was $90 \mathrm{~ms}$. The total data collection time was 177 hours. The spectrum was processed using forward linear prediction of $\sim 25 \%$ of the ${ }^{1} \mathrm{H} \omega_{3}$ complex points. 

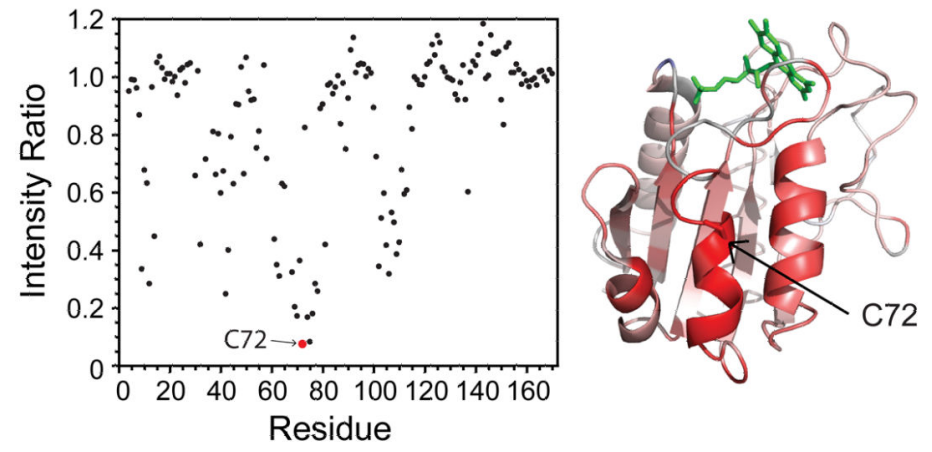

Figure 8.

Paramagnetic relaxation enhancements of MTSL-labeled flavodoxin (S57C,C55A) encapsulated in 10MAG/LDAO reverse micelles (red circles). Ratios amide ${ }^{1} \mathrm{H}-{ }^{15} \mathrm{~N}$ crosspeak intensities of oxidized MTSL (paramagnetic) and reduced MTSL (diamagnetic) labeled flavodoxin. The strongest PRE is seen at the site of label attachment (highlighted in red). PREs are color-coded on a ribbon representation of the structure of flavodoxin [78] from red (strong PRE) to white (no PRE). The flavin mononucleotide ligand is shown in stick representation (green). The location of the site of MTSL labeling (C72) is also indicated. Adapted from [38]. 


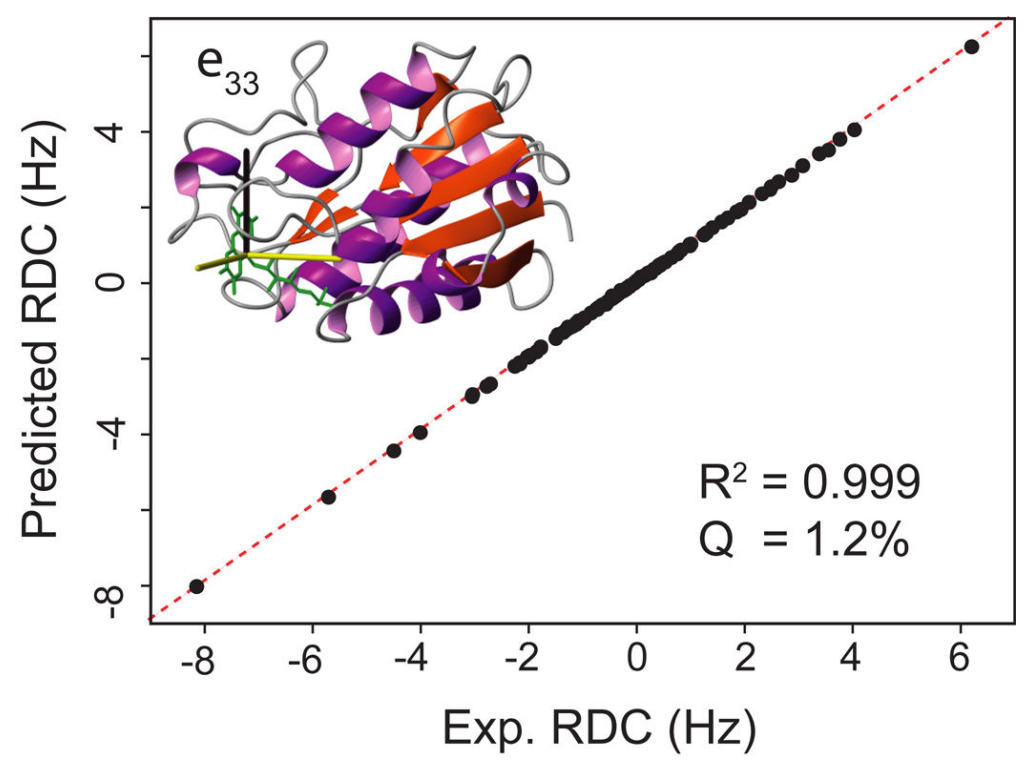

Figure 9.

Residual dipolar couplings obtained from encapsulated flavodoxin in partially aligned reverse micelles. Shown is a correlation plot of the predicted RDCs by the crystal structure [78] versus the measured RDCs for the encapsulated protein. Also shown is a ribbon representation of the protein oriented in the determined alignment tensor. Figure reproduced from Ref [26]. 
(A) $0.0=1.0=1.5 \square 2.8 \div 4.1 \div 5.5=$
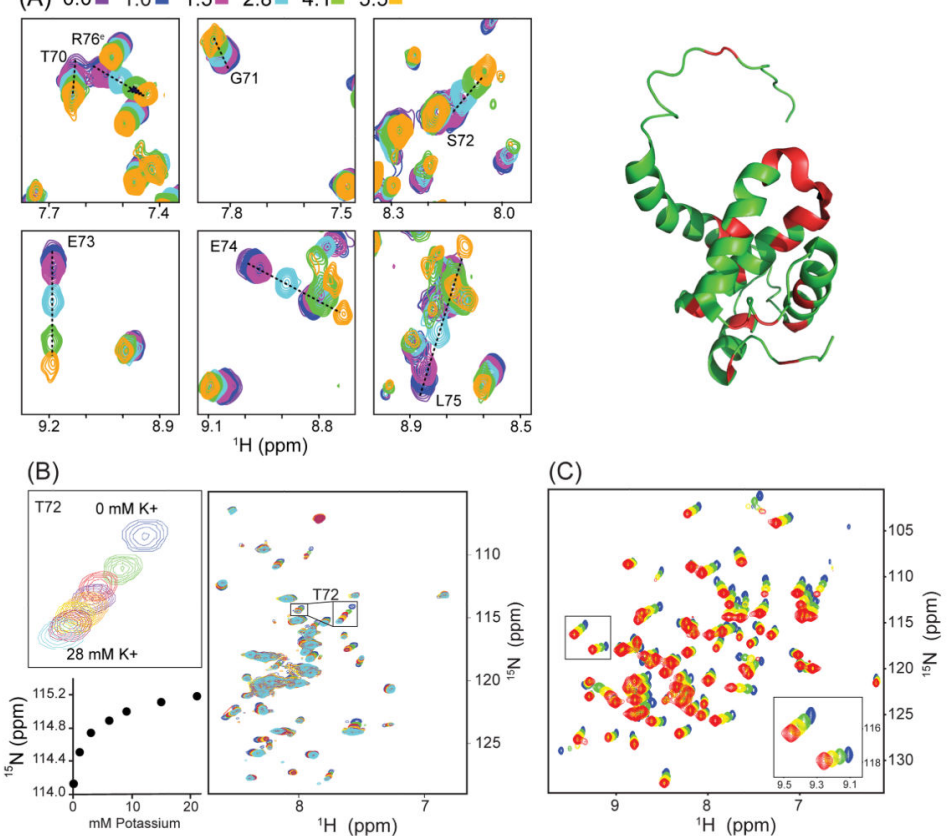

Figure 10.

Examples of biophysical experiments with encapsulated proteins. (A) Titration of myristoylated HIV-1 matrix protein encapsulated in CTAB/hexanol reverse micelles with $\mathrm{PI}(4,5) \mathrm{P}_{2}$ (mole ratios of PIP:HIV-MA are indicated) [25]. Sites whose amide ${ }^{1} \mathrm{H}^{-1}{ }^{15} \mathrm{~N}$ chemical shifts change appreciably upon binding are highlighted in red on a ribbon representation of the structure [79]. Adapted from Ref [25]. (B) Titration of the KcsA potassium channel encapsulated in $\mathrm{CTAB} / \mathrm{DHAB} /$ hexanol reverse micelles with potassium in an excess background of sodium. Adapted from Ref [23, 24] The behavior of Thr-72, a key residue in the ion selectivity filter, is also shown. These results demonstrate the functionality of the encapsulated channel. [23, 24] (C) Pressure perturbation of ubiquitin encapsulated in AOT reverse micelles in liquid pentane. Residues H68 and E64 are shown inset. Pressures shown are 1 bar (blue), 800 bar (green), 1600 bar (yellow), and 2500 bar (red). The reverse micelle retains integrity over this large pressure range though the increased viscosity of pentane at high pressure is apparent in the broadening of the amide peaks [71]. 
(A)
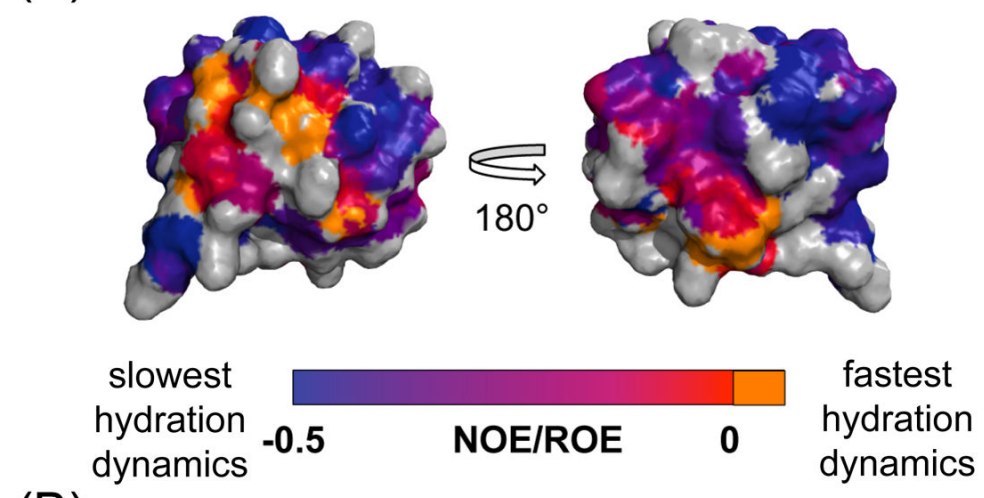

(B)

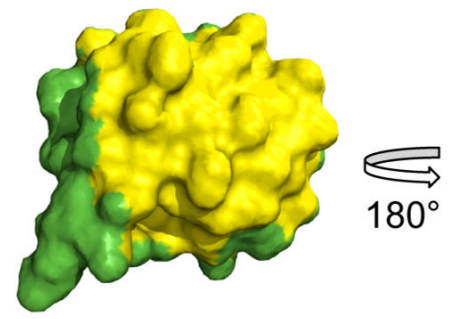

Protein-Protein Interface Surface

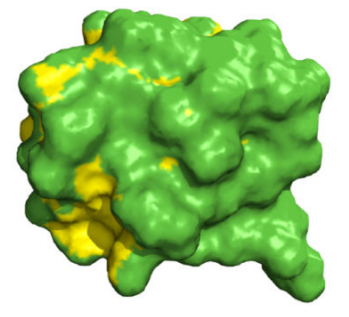

Non-Protein Interface Surface

Figure 11.

Access to protein hydration. Reverse micelle encapsulation mitigates the various technical issues that plague such measurements in bulk solution [65, 69]. ROEs and NOEs between the protein and the hydration water allow estimation of the dynamics of water at the protein surface [66]. NOE/ROE ratios are mapped to the surface of encapsulated ubiquitin (A). Slow hydration water dynamics at the surface of the protein correlate with regions of the protein that bind protein partners (B). 


\section{Table 1}

Proteins and nucleic acids successfully encapsulated in low viscosity alkanes

\begin{tabular}{|c|c|c|c|}
\hline & $\begin{array}{c}\text { MW } \\
(\mathbf{k D a})\end{array}$ & PI & $\begin{array}{l}\text { Applicable (optimal) } \\
\text { surfactant mixtures }\end{array}$ \\
\hline $\begin{array}{l}\text { Ubiquitin [18-20, } \\
\text { 22] }\end{array}$ & 8.5 & 6.8 & $\begin{array}{c}\boldsymbol{A O T} \\
\text { CTAB/HexOH } \\
\text { C12E4/AOT/DTAB } \\
\text { 10MAG/LDAO }\end{array}$ \\
\hline $\begin{array}{c}\text { Cytochrome c }[18, \\
20,21]\end{array}$ & 12.3 & 10 & $\begin{array}{c}\text { CTAB/HexOH } \\
\text { C12E4/AOT/DTAB } \\
\text { I0MAG/LDAO }\end{array}$ \\
\hline $\begin{array}{c}\text { Staphylococcal } \\
\text { nuclease } \Delta+\mathrm{PHS}\end{array}$ & 16.1 & 9.2 & $\begin{array}{c}\text { CTAB/HexOH } \\
\text { C12E4/AOT/DTAB } \\
\text { 10MAG/LDAO }\end{array}$ \\
\hline T4 lysozyme & 18.6 & 9.8 & $\begin{array}{c}\mathrm{C} 12 \mathrm{E} 4 / \mathrm{AOT} / \mathrm{DTAB} \\
\mathbf{1 0 M A G / L D A O}\end{array}$ \\
\hline $\begin{array}{l}\text { Hen Egg White } \\
\text { Lysozyme }\end{array}$ & 14.4 & 11.3 & $\begin{array}{l}\mathrm{CTAB} / \mathrm{HexOH} \\
\text { I0MAG/LDAO }\end{array}$ \\
\hline Flavodoxin $[20,21]$ & 19 & 4.2 & $\begin{array}{c}\text { CTAB/HexOH } \\
\text { C12E4/AOT/DTAB } \\
\text { 10MAG/LDAO }\end{array}$ \\
\hline $\begin{array}{c}\text { Dihydrofolate } \\
\text { reductase (human) } \\
{[22]}\end{array}$ & 18 & 4.8 & $\begin{array}{l}\mathrm{CTAB} / \mathrm{HexOH} \\
\text { I0MAG/LDAO }\end{array}$ \\
\hline $\begin{array}{l}\text { Aldoketoreductase } \\
1 \mathrm{C} 2[20]\end{array}$ & 36.7 & 7.1 & IOMAG/LDAO \\
\hline $\begin{array}{c}\text { Arginine Kinase } \\
{[20]}\end{array}$ & 40.2 & 6.0 & IOMAG/LDAO \\
\hline $\begin{array}{c}\text { Maltose-Binding } \\
\text { Protein }[20,22,31]\end{array}$ & 40.8 & 5.2 & $\begin{array}{l}\mathrm{CTAB} / \mathrm{HexOH} \\
\text { I0MAG/LDAO }\end{array}$ \\
\hline $\operatorname{eGFP}^{*}[21]$ & 54 & 5.6 & $\begin{array}{l}\mathrm{CTAB} / \mathrm{HexOH} \\
\text { I0MAG/LDAO }\end{array}$ \\
\hline $\begin{array}{c}\text { Malate Synthase G } \\
{[20,22]}\end{array}$ & 81.4 & 5.9 & $\begin{array}{l}\mathrm{CTAB} / \mathrm{HexOH} \\
\text { I0MAG/LDAO }\end{array}$ \\
\hline $\operatorname{DsRed} 2+{ }^{* \dagger}$ & 103 & 6.2 & СТАВ/НехОН \\
\hline $\begin{array}{l}\text { HIV-1 matrix } \\
\text { protein }^{\dagger}[25]\end{array}$ & 14.7 & 9.1 & СТАВ/НехОН \\
\hline Recoverin [25] & 26.9 & 5.7 & $\begin{array}{l}\mathrm{CTAB} / \mathrm{HexOH} \\
\text { I0MAG/LDAO }\end{array}$ \\
\hline $\mathrm{KcsA}^{* \dagger}[23,24]$ & 54 & 10.5 & СТАВ/DHAB/НехОН \\
\hline tRNA $^{\text {val }}[20]$ & 27 & n.d. & IOMAG/LDAO \\
\hline HIV tetraTAR $^{\dagger}$ & 8.5 & n.d. & СТАВ/НехОН \\
\hline $\mathrm{U} 4$ snRNA $^{\dagger}$ & 7.4 & n.d. & СТАВ/НехОН \\
\hline
\end{tabular}

* Sizes listed for these proteins are for the multimeric state. Monomer sizes are: eGFP $-27 \mathrm{kDa}$, DsRed2+ -25.8 kDa, KcsA - 13.5 kDa.

${ }^{\dagger}$ These molecules have not been tested in the 10MAG/LDAO mixture. 